\title{
أثثر توظيف تقنية البودكاست في تنمية مهارة الاستماع في مادة اللغة الإنجليزية لدى طلاب الصف الأول بمحافظة جنوب الباطنة مادة الإنجة
}

\section{إيمان بنت محمد بن زيد المعولية}

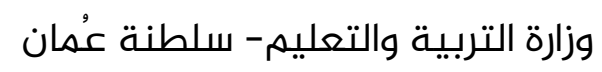

qazaqmah@yahoo.com 


\title{
أثرتوظيف تقنية البودكاست في تنمية مهارة الاستماع في مادة اللغة الإنجليزية لدى طلاب الصف الأول بمحافظة جنوب الباطنة
}

\author{
إيمان بنت محممد بن زيد المعولية \\ وزارة التربية والتعليم- سلطنة عُمان بمان \\ qazaqmah@yahoo.com
}

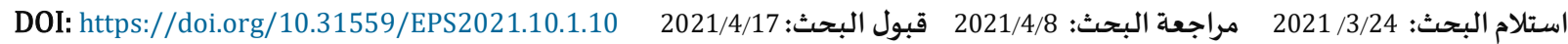

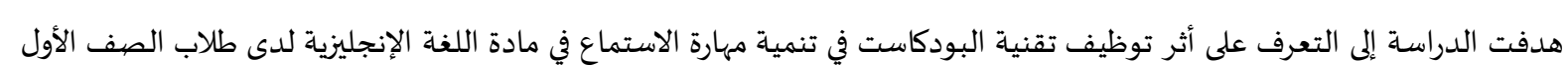

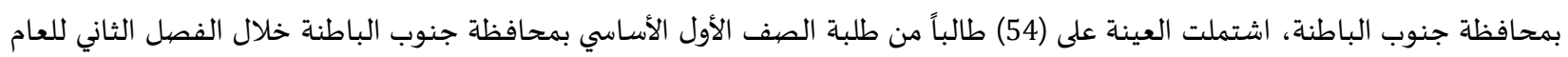

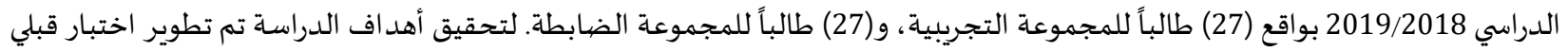

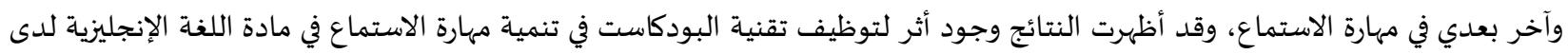

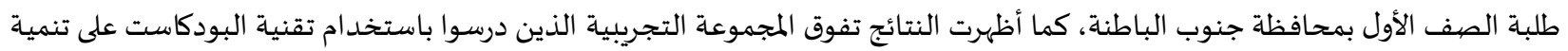

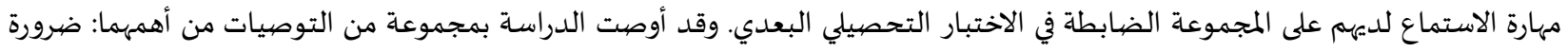

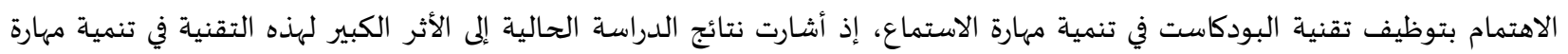
الاستماع لدى طلبة الصف الأول.

الكلمات المفتاحية: تقنية البودكاست؛ مهارة الاستماع؛ اللغة الإنجليزية.
\end{abstract}

يُعد الاهتمام بالمرحلة الأساسية من أهم أولويات أنظمة التعليم في العالم، نظراً لأهمية هذه المرحلة في إعداد الطلبة، وتعليمهم أهم المبادئ

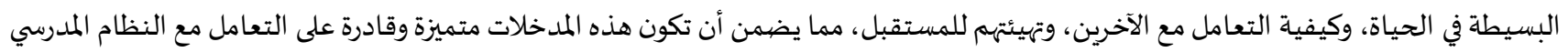
بشكل مباشر. وقد ركزت المناهج التربوية الحديثة على الطالب، وجعلته محوراً للعملية التعليمية، فهو الذي يقوم بأداء المهمات، والتوصل إلى النتائج، مما

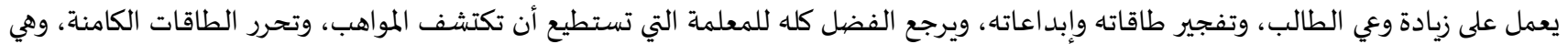

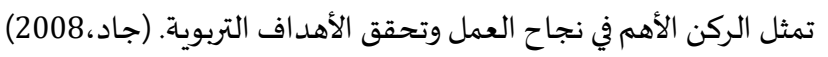

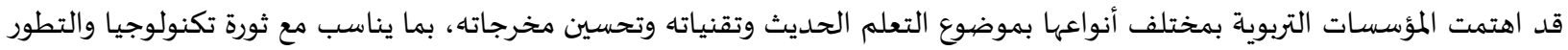

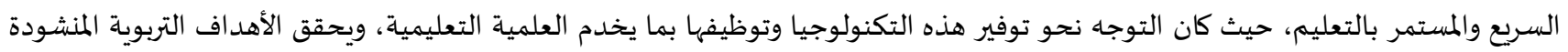
الأثر الكبير في المسيرة التعليمية. (Al- Qasim \& Al- Fadda, 2013) 
من هنا جاء الاهتمام بالتقنيات التربوية الحديثة بمختلف أنواعها، كتقنية البودكاست التي أثبتت فاعليتها في العملية التعليمياة، من خلال

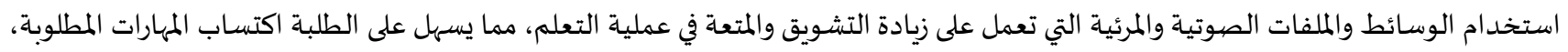
ويعزز فهمهه واستيعابهم للأفكار المراد تعلمها، بإضافة إلى تقديم حلول لمشـاكل تعلم مهارة الاستماع في فئية مادة اللغة الإنجليزية. (الحربي، 2016)

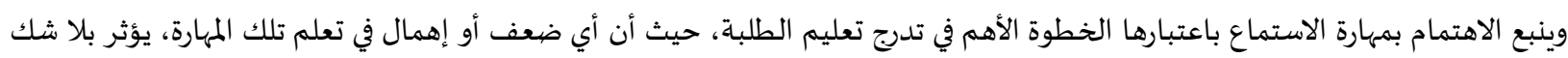

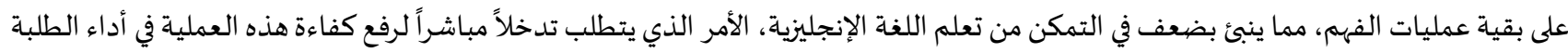

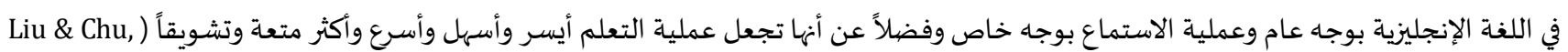

إن تعليم اللغة الإنجليزية يعدُّ من الركائز المهمة التي تعتمد عليها العملية التعليمية في سلطنة عُمان، وخاصة في نظام التعليم الأسـاسي الذي الذي الذيا

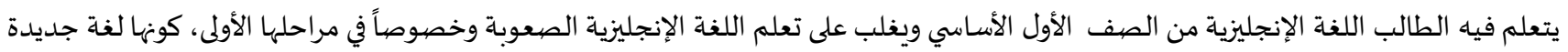

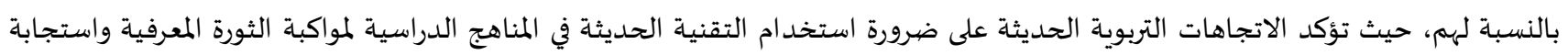
لحاجات المتعلمين واهتماماتهم، من أجل تحسين مخرجات العملية التعليمية ورفع المستوى التحصيلي للطلبة.

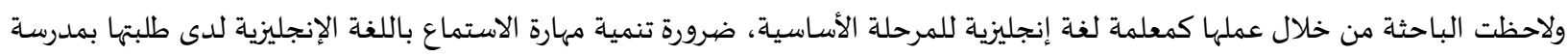

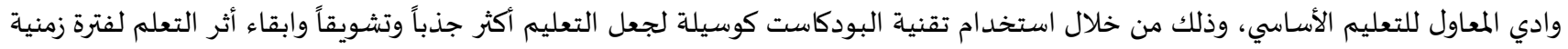

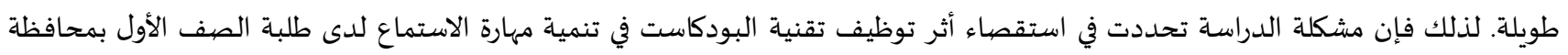
جنوب الباطنة.

2.1 أسئلة الدراسة:

تتلخص مشكلة الدراسة في الإجابة عما يلي:

ما أثر توظيف تقنية البودكاست في تنمية مهارة الاستماع لدى طلاب الصف الأول بمحافظة جنوب الباطنة؟ هل توجد فروق بين متوسطي درجات طلاب المجموعة التجريبية الذين درسوا باستخدام تقنية البودكاست في القياسين القبلي والبعدي لصالح القياس البعدي؟

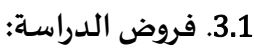

تسعى الدراسة إلى فحص الفروض الآتية:

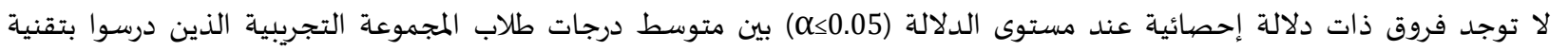

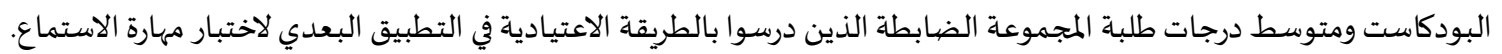
لا توجد فروق ذات دلالة إحصائية (0.05) بين متوسطي درجات طلاب المجموعة التجريبية الذين درسوا باستخدام تقنية البودكاست وفي القياسين القبلي والبعدي لصالح القياس البعدي.

4.1 - 2.1 أهداف الدراسـة:

يكمن هدف الدراسة في التعرف على أثر توظيف تقنية البودكاست في تنمية مهارة الاستماع لدى طلبة الصف الأول بمحافظة جنوب الباطنة.

5.1 أهمية الدراسـة:

تتضح أهمية الدراسـة الحالي في النقاط التالية:

الاستفادة من مستحدثات التقنية التربوية المتنوعة لخلق جيل جديد مواكب لمتغيرات العصبه العصر الحديث.

مراعاة الفروق الفردية بين الطلبة من خلال تفريد التعليم، وجعل عملية التعلم أكثر متعة وأعظم فائدة مع الاحتفاظ بأثر التعلم لفترة زمنية أطول. التعرف على أثر توظيف تقنية البودكاست في تنمية مهارة الاستماع باللغة الإنجليزية لدى طلبة الصف الأول الأساسي وبيان أثر ذلك على الع العمان مخرجات العملية التعليمية. من المؤمل أن يستفيد منها معلمو المرحلة الأسـاسية بصورة عامة ومعلمي اللغة الإنجليزية بصورة خاصة الذين يستخدمون الطرق التقليدية في التدريس على توظيف التقنيات الحديثة (البودكاست) في العملية التعليمية. 
6.1 - 2.1 - مدود الدراسة:

الحدود الموضوعية: تتحدد الحدود الموضوعية من خلال تناول توظيف تقنية البودكاست في تنمية مهارة الاستماع لدى طلبة الصف الأول

بمحافظة جنوب الباطنة.

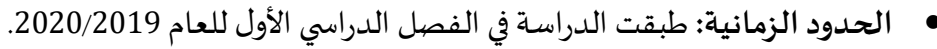
• الحدود البشرية: طبقت الدراسة على عينة من طلاب الصف الصف الأول الأسـاسي. • الحدود المكانية: طبقت الدراسة في مدرسة وادي المعاول للتعليم الأساسي التابعة لمحافظة جنوب الباطنة.

0.1 تقنية البودكاست: يعرفها الخليفة(2010:55) أهها: "تقنية تقوم أسـاساً على فكرة التدوين الصوتي والمرئي، ونشره عبر الإنترنت أو تسجيله على ألى

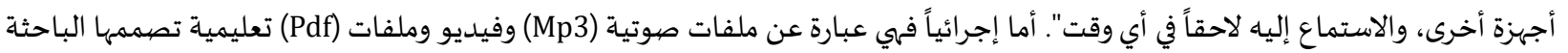

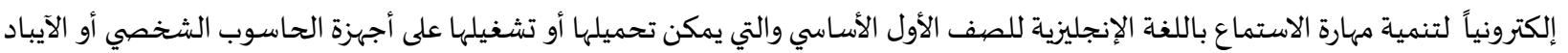

(whatsApp) والاستماع هاتف نقال يحتوي على متصفح إلها ومشاهدتها في أي وقت وفي أي مكان.

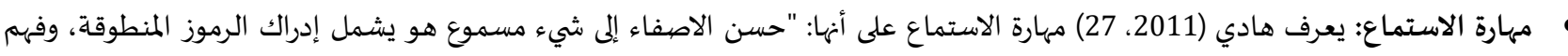
مدلولها، وتحديد الوظيفة الاتصالية المتضمنة في الرموز أن الكلام المنطوق". أما إجرائياً تعرف على أنها الدرجة التي يحصل عليها الطالب في الاختبار التحصيلي لمهارة الاستماع في مادة اللغة الإنجليزية والمعدد من قبل الباحثة.

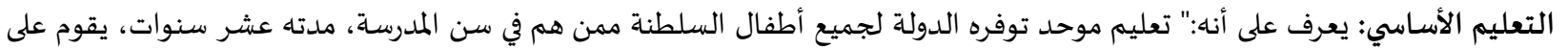

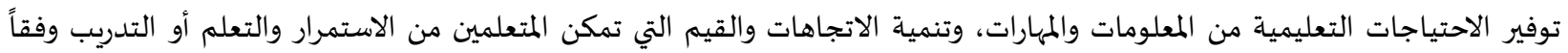

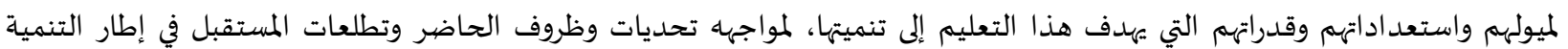
المجتمعياة الشاملة" (وزارة التربية والتعليم، 3:2001).

2. 2 الإطار النظري: تناول الإطار النظري بعض الموضوعات التي تشير إلى تكنولوجيا التعليم وأهميتها في تطوير أنماط التعليم ومنها توظيف تقنية البودكاست في عملية التعلم في العديد من المقررات للطلبة في مختلف البيئات المدرسية، وفيما يلي عرض للإطار النظري:

1.2. أهمية تكنولوجيا التعليم على العملية التعليمية: أسهمت تكنولوجيا التعليم في فرز أنماط جديدة من التعلم، وكان لها الدوليها لهور الأكبر في الاستفادة منها في تحسين مخرجات التعليم، ولاسيما في توظيف العديد من التقنيات الحديثة والتي أشارت إلهها العديد من الدراسات سواء في عملية التحصيل أو التفكير أو اكتساب المهارات.

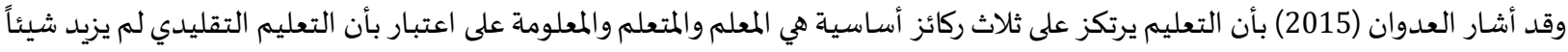

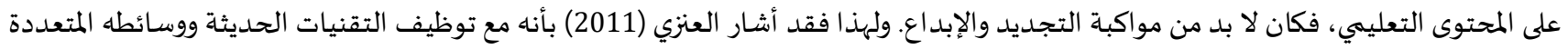
من صهوت وصورة وأقراص مدمجة أسهمت في تطوير أنماط التعلم. فكان لتوظيف التقنيات الحديثة الأثر الواضح في القطاع التعليمي والذي انتشرت

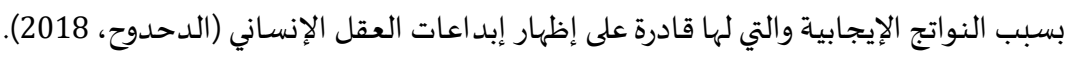
فقد أوضح آل سرور (2018) بأن تطوير عملية التعليم تعد من الأمور المهمة نتيجة للتحديات، وأن تنمية مهارات المعلمين قادرة على توظيف التكنولوجيا والارتقاء بالعملية التعليمية وتحسين مخرجاتها، كما أصبح من الضروري تشجيع المعلمين على توظيف التكنولوجيا في مختلف المواد

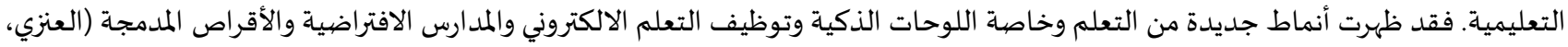

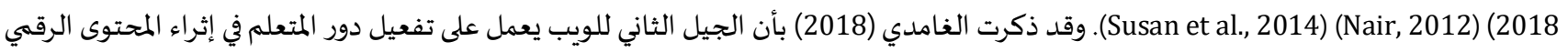
على الانترنت والتعاون في بناء مجتمعات الكترونية وتعكس هذه التطبيقات خصائص الجيل الثاني للويب ومن أبرزها المدونات والشبكات الاجتماعية والبودكاست. ويلاحظ مما سبق بأن تطور التكنولوجيا أفرز إلى ظهور أنماط جديدة من عملية التعلم وساعدت المؤسسات التعليمية على تطوير الآليات نحو انتاج مخرجات جديدة تهدف في خلق جيل مسلح بالعلم وقادر على مسايرة كافة التحديات والعلوم الحديثة.

2.2. تقنية البودكاست (Podcast): تعد تقنية البودكاست من التقنيات التي ظهرت في أواخر عام (2004)، حيث انتشر استخدامها في العملية التعليمية من خلال تسجيل المحاضرات وإعادة بثها وغالباً ما تستخدم في تعليم اللغات والتدريب بسبب إمكانية عادة تشغلها عدة مرات حسب رغبت رغبة الطالب. 
وتعد تقنية البودكاست (Podcast) إحدى التطبيقات التي تستخدم سلسلة ملفات ووسائط متعددة صوتية أو مرئية منها، والتي تبث عبر قناة

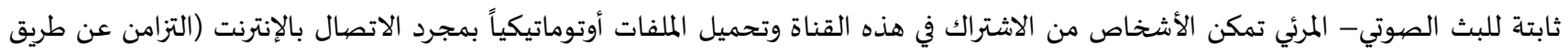
الويب) (هارون، (2013).

وأشار ستانلي (Stanley, 2005) بأن تقنية البودكاست عبارة عن برامج مسموعة أو مرئية على الشبكة العنكبوتية في ملفات صوتية بامتداد

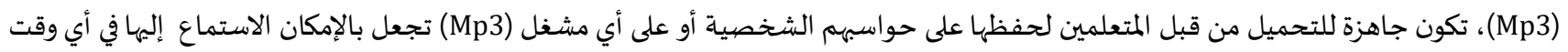

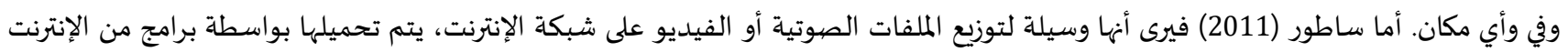

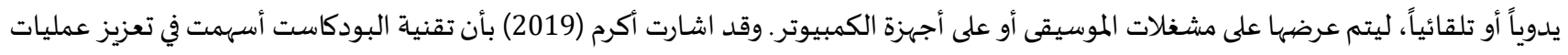

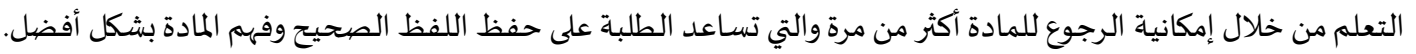

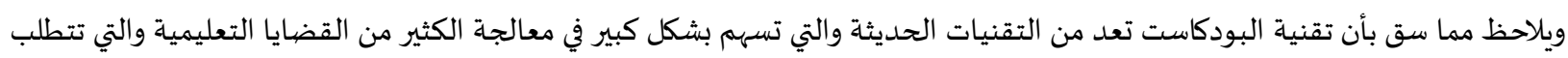
النطق الصحيح وخاصة في تعليم اللغات وقراءة القرآن الكريم.

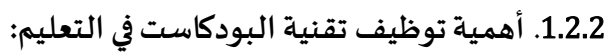

مع التطور التكنولوجي أصبح من الضروري العمل على تحسين أنماط التعلم من خلال توظيف التقنيات بصورة عملية. وقد ذكر سلامة (2018)

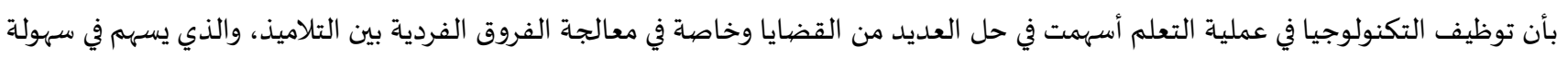
إعادة عرض المادة أكثر من مرة بهدف تسهيل وفهم المعلومة من قبل الطلبة بطريقة ممتعاة. وأن استخدام التكنولوجيا عزز من إقبال الطلبة على فيلى

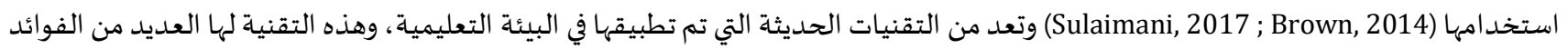
والتي بينها كل من كامل (2005) وعماشـة والشايع (2012) وأكرم (2019) ونجملهـا بما يلئ:

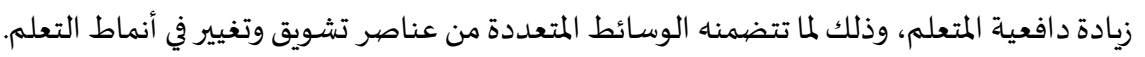

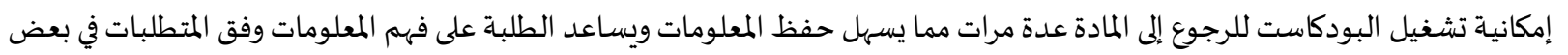

جذب انتباه الطلبة وتشويقهم للتعليم، من خلال استخدام العديد من الأدوات الحديثة والتي من شأنها أن تدفع الطلبة في عملية التعلم.

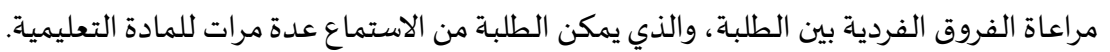
إمكانية استخدا مها بشكل فردي أو جماعي. الاحتفاظ بأثر التعلم لفترة طويلة من الزمن، بالإضيافة إلى تقليل من تكاليف العملية التعلية إنيمية والتقليل من تكاليف التنقل من وإلى المدرسـة بالنسبة للطلبة. ويذكر لاينج (Laning, 2007) بأن أهمية استخدام البودكاست في العملية التعليمية والتي تمكن الطلبة من إمكانية الاستماع والمشاهدة في أي

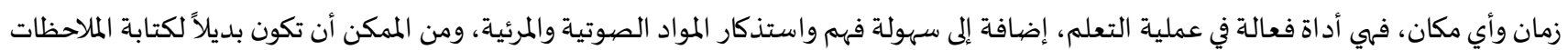
داخل المحاضرة. ويلاحظ مما سبق بأن أهمية البودكاست تعد ذات أهمية كبيرة لأنها تخرج الطلبة من التعلم التقليدي إلى تعلم شيق وجذاب والذي من شأنه أن يزيد من مستوى تعلمهم ويدفههم إلى اعتمادهم على الذات لأن المادة التعليمية في تطبيق البودكاست تكون مسجلة والتي تمكنهم من الرجوع إلهيها عدة مئه

أن تقنية البودكاست تنوع استخدامها في البيئة التعليمية. وهناك العديد من المجالات التي يمكن استخدام التحات تقنية البودكاست فهيها، والتي تتنوع ما

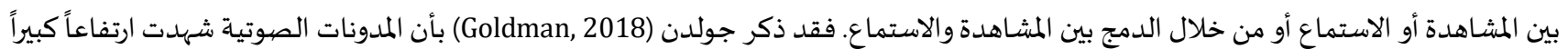

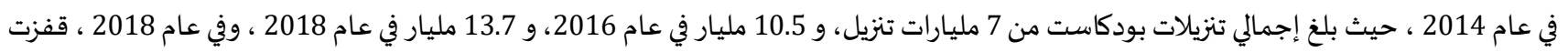

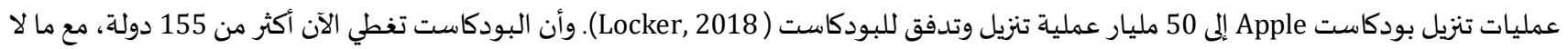

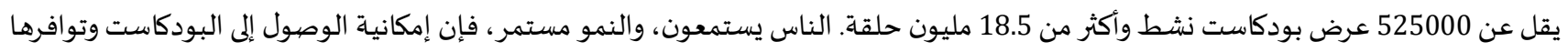

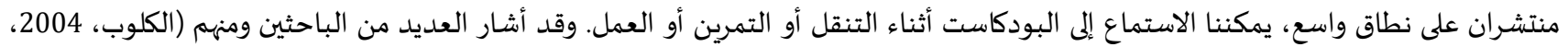

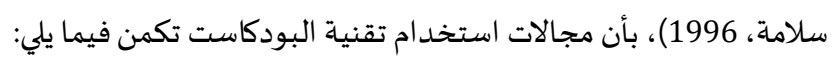
سهولة تسجيل المادة التعليمية لمصاحبة للمواد التعليمية كالشرائح الشفافة. تسجيل محاضرات وندوات ودروس بشكل علمي والرجوع إليها وقت الحاجة. 
تسجيل الكتب بمختلف أنواعها كالقرآن الكريم والكتب والقصص العالمية وقصص الأطفال بالإضافة إلى بعض الدوس التي تعد مهمة لتعليم وإطلاع الطلبة عليها خاصة إذا كانت من المواد العلمية المصورة. تسجيل المقابلات الشخصية حيث توفر الكثير من الوقت وكتابة ما يدور فيها من معلومات والتي تعد بمثابة معلومات ومعارف تسهم في تعزيز الأدب النظري في بعض المواقف. معالجة عيوب النطق وتعلم النطق الصحيح عند بعض الطلبة خاصة في تعلم الكثير من اللغات والمخارج والتي تتطلب تطبيق الفظ الصحيح.

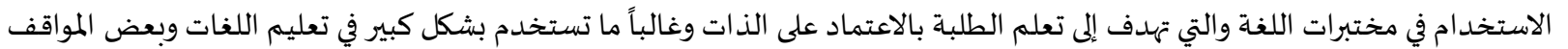
الأخرى. ويلاحظ مما سبق بأن استخدام تطبيق البودكاست يعد ذات فائدة كبيرة للبيئة التعليمية لمختلف المستويات التعليمية، لأنها تحتوي على الكثير

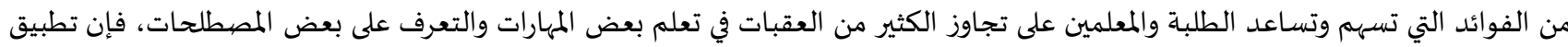
البودكاست اسهم في فهم الطلبة للكثير من المعاني والمفاهيم واللفظ للعديد من المصطلحات وتهات وخاصة فئ في اللغة الانجليزية.

3.2 مهارة الاستماع: تشير مهارة الاستماع إلى الانتباه وحسن الإصغاء إلى بعض المواد بالإضيافة إلى إدراك الرموز اللغوية المنطوقة وفهم مدلولها وتفاعل الخبرات المحمولة في هذه الرموز مع خبرات المستمع وقيماه ومعاييره.

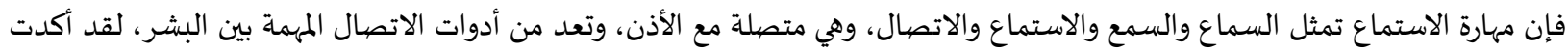

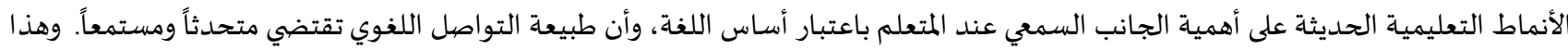

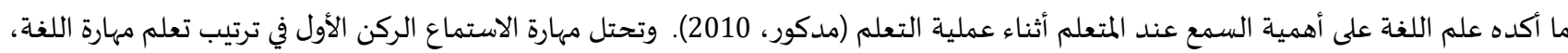

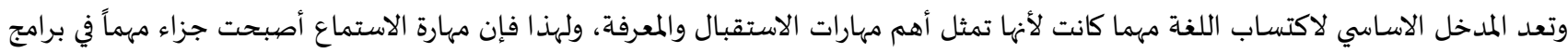

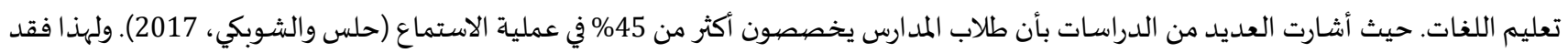
أشار خطايبة (2000) بأن تعليم اللغة الإنجليزية يتطلب استخدام التقنيات الحديثة في تطوير أساليب تدريسها وخاصة وأن الأجهزة توفر العيد من الحلول المناسبة لاسيما في مهارة الاستماع والتعرف على النطق الصحيم.

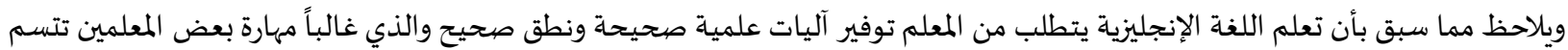
بالضعف في اللفظ الصحيح لمفردات اللغة وخاصة اللغة الإنجليزية بصورة صحيحة. وعليه فإن توظيف التقنيات التعليمية وتنمية مهارة الاستماع من شأنه أن يطور ويتحسن عملية التعلم اللغة الإنجليزي من قبل الطلبة.

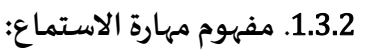
لغنة: " السمع هوم: ما ما قر في الأذن من شيء سمعاء، ويقال: ساء سمعان، فأساء إجابة، أي لم يسمع حسناً. كما يقصد بالمعنى اللغوي أن الاستماع

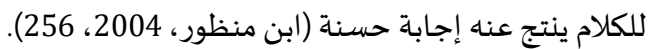

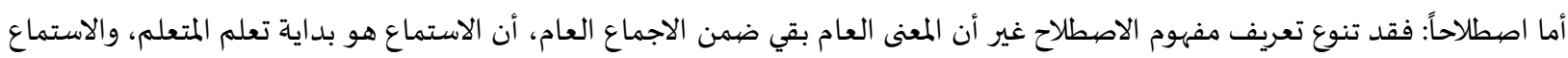
يعد من أهم عناصر الحواس في البشر وأنه من العناصر الأساسية في عملية التواصل مع الآخرين. فقد عرفه عطية (2008، 217) بأنه: "عملية إنسـانية ذهنية واعية مقصيودة ترمي إلى تحقيق غرض اهن معين يسعى إليه السـامع، تشترك فياء الأذن والدماغ". ويلاحظ مما سبق بأن مهارة الاستماع تشير إلى قدرة الطلبة على تعلم النطق الصحيح من خلال ما يتم بثه بصورة مقصيودة داخل البيئة

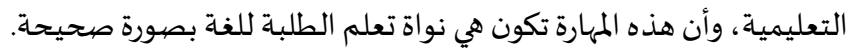

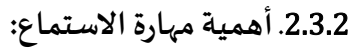
تعد مهارة الاستماع من أهم الوسائل التي يعتمد عليها الطلبة في اكتساب المفردات والعلوم المختلفاعة، كما أن سماع الكلمات من شأنه أن يزيد من قدرته على التغبير دون الكتابة وتسهم في زيادة معارفه العلمية واللفظية الصحيحة. وفي البيئة التعليمية غالباً ما تكون لمهارة الاستماع الطلبة الطاتية

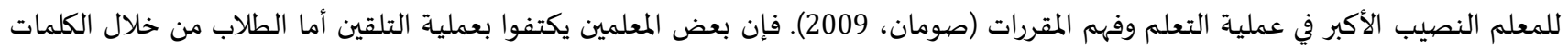
المسموعة (عطية، 2008). وقد ذكر مزيد (2012) بأن أهمية الاستماع لدى الطلبة تتمثل فيما يلي: قدرة الطلبة على التمييز بين الأصوات والحروف واللفظ الصحيح للكلمات.

إثر محصلة الطلبة اللغوية بالعديد من المعاني والألفاظ والعبارات وبيان الصحيح منها. تنمية التفكير النقدي لدى الطلبة عبر ما يسمعاه من آراء واتجاهات وأفكار مختلفة في يتعلق ببعض المواضيع. مساعدة الطلبة على تنظيم الأفكار بصورة مرتبة ومنطقية. 
تنمية الذاكر السمعية للطلبة والاحتفاظ بالمعلومات وتوظيفها في العديد من الأماكن.

تنمية اللغة الشفوية والمنطوقة لطلبة بصورة علمية صحيحة.

فالاستماع أسـاسي في استيعاب وتحصيل التلميذ فأحيانا يتأخر التلميذ.

يلاحظ مما سبق بأن أهمية الاستماع تعد من المنطلقات الأساسية نحو تعلم الطلبة في كافة المراحل إلى المزيد من العلوم بالإضيافة إلى تعلم

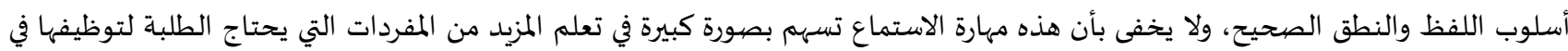
مختلف مراحل الحياة ومختلف العلوم.

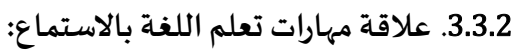

أن تعلم اللغات لغير الناطقين بها تتطلب جهداً مميزاً من قبل الطلبة أو من قبل المعلمين، وغير أن الجهد الأكبر يقع على عاتق الطلبة، ولهذا فإن إن

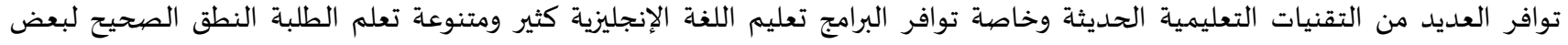

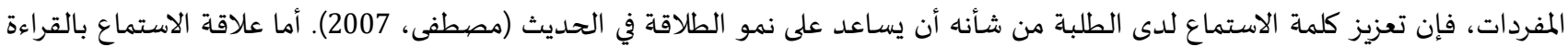
فالاستماع هو الأساس للتعلم اللفظي الصحيح خاصة في بعض مخارج الحروف والتي تتطلب إعادة سماع اللفظ عدة مرات على يتمكن الطلبة من

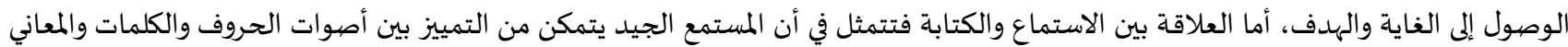
فيستطيع كتابتها بشكل صحيح، كما أن مهارة الاستماع تمكن الطلبة من زيادة مفرداتهم اللفظية وينعكس بصهورة إيجابية في التعبير الكتابي واللفظي لهم (الخوسيكي، 2010). إن العلاقة التي تتميز بها مهارة الاستماع تمثل الجانب النظري الذي يتمكن من خلال الطلبة من الوصهول إلى المزيد من المفردات الصحيحة

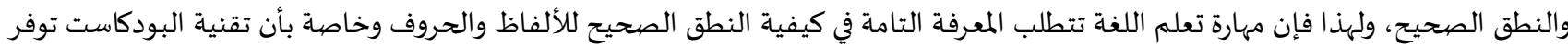
آلية معرفة اللفظ الصحيح ويمكن للطلبة من الرجوع إلى الاستماع عدة مرات إلى بعض المفردات والتي غالباً ما تكون فيها صعوبة في عملية النطق.

4.2. تعليم اللغة الإنجليزية في سلطنة عُمان: يتم تدريس اللغة الإنجليزية في المرحلة الأولى في سلطنة عُمان وفق نظامين متوازيين، يمثل الأول نظام التعليم العام. أما الثاني يمثل النظام التربوي المطور تحت مسمى (التعلم الأسـاسي) وفيما يلي نبذة عن واقع اللغة الإنجليزية في نظام التعليم الأساسي، فقد قامت السلطنة بإدخال اللغة

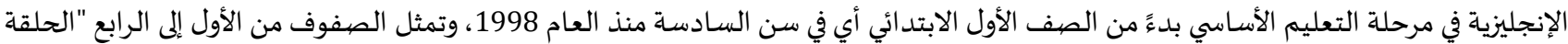
الأولى" من هذه المرحلة كما تشمل الخطة سبع حصص أسبوعية لكل سنة دراسية، وقد صمئة من منهج اللغة الإنجليزية الجديد( English for me)،

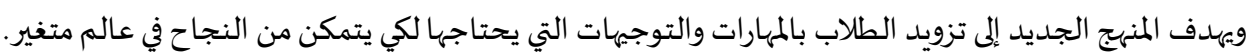

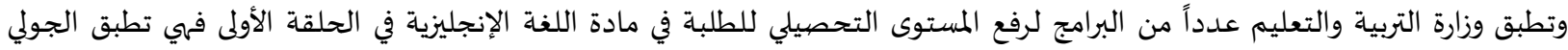

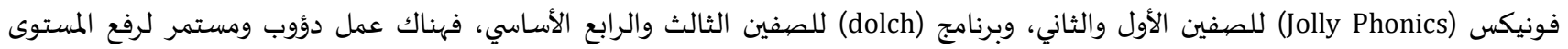
التحصيلي للطلبة(البدري، 2017). وأشار برادي وآخرون (Bradyb et al., 2009) أن أهمية تقنية البودكاست في تعلم اللغة الإنجليزية على النحو الآتي:

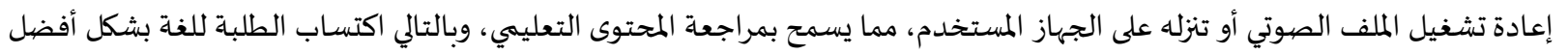
لغير الناطقين بها. إمكانية ربط الملف الصوتي بالصور الداعمة للمحتوى وروابط مصادر التعلم المعلومات أو ربط الملف الصهوتي بالأفلام التي تسمح للمعلم باستخدام المرئيات لإيجاد مصادر تعليمية تتناسب مع طبيعة الطلبة وطرق تعلمههم. استخدام البودكاست كأداة تتفاعل مع مهمات طرق التعلم، كاستخدام طرق تدريسية تعتمد على النموذج البنائي في التعلم أو النماذج الموجة للفرد الشخصي. عوائد عامة للبودكاست وخاصة في إدارة الوقت تبعاً لاحتياجات الفئة المستهدفة سواء من قبل المعلم أو الطالب، بحيث توفر للطالب وقت التعلم المناسب وإدارته بنفسـه. ومما سبق يتضح بأن تعليم اللغة الإنجليزية يحتاج إلى جهد كبير من قبل المعلم لأن معظم الطلبة لديهيم نفور من هذا المقرر لصعوبة دراستهاه، فإن اللجوء إلى المعلم عدة مرات ربما يعرضهه إلى مزيد من الاحراج، ولكن مع تطبيق البودكاست أتاح المجال للطلبة إلى تسجيل المادة والرجوع إلهيها وقت مئه

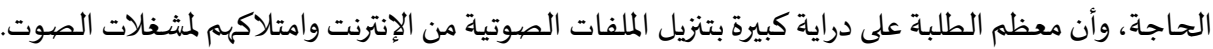

5.2

نظراً لحداثة تقنية البودكاست في المجال التربوي فإن هناك القليل من الدراسات في البيئة العربية التي تناولت هذه التنقية في مجال التعليم في مقررات متنوعة وظفت البودكاست في مقرر اللغة الإنجليزية. فيما يلي عرض الدراسات السابقة العربية ومنها والأجنبية مرتبة من الأحدث إلى الأقدم: 
فقد أجرت الحارثي (2018) دراسة للكشف عن أثر توظيف تقنية البودكاست في بيئة التعلم النقال على التحصيل الدراسي في مقرر الإحياء لدى

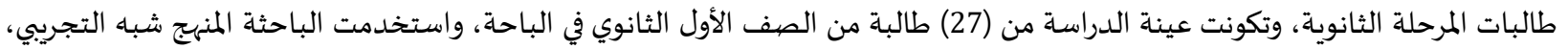

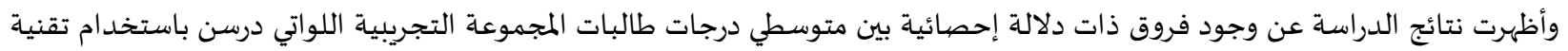
البودكاست في التطبيقين القبلي والبعدي للاختبار التحصيلي عند مستوى التذكر والفهه والتطبيق والاختبار التحصيلي ككل لصالح الاختبار البعدي.

وقامت الغامدي (2018) بدراسة هدفت الكشف عن فاعلية البودكاست التعليمي في تنمية مهارة التحدث باللغة الإنجليزية لدى طالبات المرحلة المتوسطة بالباحة، وتكونت عينة الدراسة من والبالغ (44) طالبة تم اختيارهم بالطريقة قصدية، ولتحقيق أهداف الدراسة تم استخدام بطاقة

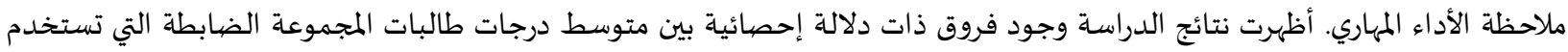
الطريقة التقليدية ومتوسط درجات المجموعة التجريبية التي تستخدم البودكاست التعليمي في القياس البعدي في بطاقة ملاحظة مهارة التحدث باللغة الإنجليزية لصالح المجموعة التجريبية. وفي دراسـة أخرى قام بها المشهراوي (2017) هدفت إلى التعرف على فاعلية برنامج قائم على الوسائط المتعددة في تنمية مهارات الاستماع لدى الدي طلاب الصف السادس الأساسي، ولتحقيق هدف الدراسة أستخدم الباحث المنهج التجريبي، وقد صمم الباحث أدوات الدراسة برنامج قائم على

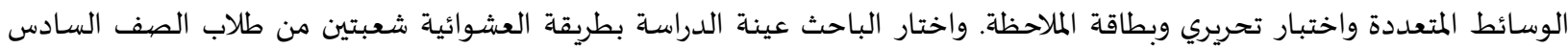
الأساسي. وقد توصلت الدراسة إلى وجود فروق ذات دلالة إحصائية عند مستوى دلالة بين متوسط درجات طلاب المجموعة التجريبية ودرجات

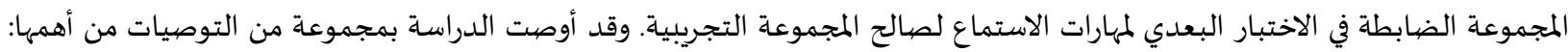

تصيميم وإنتاج برامج وسائط متعددة المباحث الدراسة ولذلك لتنمية مهارات الاستماع بمختلف المواد التعليمية وزيادة التحصيل الدراسي. وقامت الحربي (2016) بدراسة هدفت إلى التعرف على فاعلية القصص الرقمية في تنمية مهارات الاستماع النافد في مقرر اللغة الإنجليزية لدى

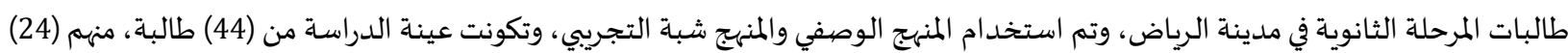
طالبة في المجموعة التجريبية التي درست باستخدام القصص الرقمية، و(20) طالبة من المجموعة الضابطة التي درست بالطريقة التقليدية. وأظهرت نتائج الدراسة إن التدريس باستخد ام القصص الرقمية ذا فاعلية كبيرة في تنمية مهارات الإسماع الناقد لدى لدى طالبات المرحلة الثانوية في مقرر مادة اللغة الإنجليزية في مدينة الرياض. أما دراسة أبو المعاطي وآخرون (2015) هدفت التعرف على مهارات الاستماع باللغة الإنجليزية والكشف عن أثر تصميم كائنات تعلم رقمية

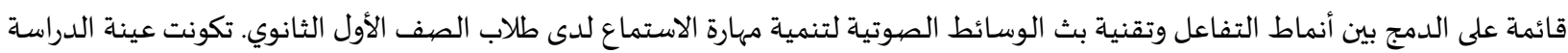
من(60) طالباً، وتم استخدام المنهج شبه التجريبي، وأظهرت نتائج الدراسة وجود فروق ذات دلالة إحصيائية للمجموعة التجريبية الثانية التي

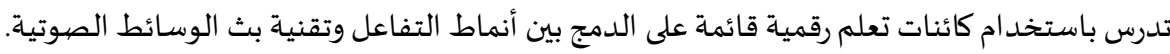
كما قام ناجون (Nguyen, 2011) دراسة هدفت الكشف عن فاعلية البودكاست في تنمية مقرر كتابة اللغة الإنجليزية من خارج ولاية كاليفورنيا، واستخدمت الدراسة المنهج شبة التجريبي، وتكونت عينة الدراسة من (41) طالباً قسموا على المجموعتين أحدهما تجريبية وعددهم (18) طالباً

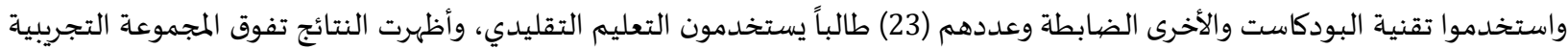
التي استخدمت أداة تقنية البودكاست في اختبار الكتابة على المجموعة الضيابطة التي استخدمت وعت التعلم التقليدي. كما قام ليفيتن وماسيثون وبنينك (Levitan, Mathison \& Billings, 2010) بدراسـة هدفت التعرف على فاعلية تقنية البودكاست في تنمية أداء طلاب الصف الثالث الابتدائي في اللغة الإنجليزية بولاية كاليفورنيا، ولتحقيق أهداف الدراسة استخدم الباحثين المنهج شبه التجريبي،

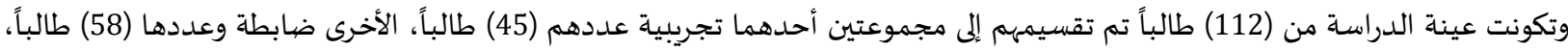
وأظهرت نتائج الدراسة إلى تفوق المجموعة التجريبية التي استخدمت تقنية البودكاست في مهارة فهم اللغويات على المجموعة الضابطة التي استخدمت التعليم التقليدي. بينما هدفت دارسة خاني و أبو ناجدين (Khany \& abo-Nejadian, 2010) الكشف عن أثر تقنية البودكاست في تنمية مهارة الاستماع لدى المتعلمين الإيرانيين، ولتحقيق أهداف الدراسة استخدمت الباحثة المنهج الوصفي شبه التجريبي، تكونت عينة الدراسة من(60) طالباً تم تقسيمهم إلى مجموعتين أحدهما تجريبية عددها (30) طالباً يستخدمون ملفات صوتية (البودكاست)، والأخرى الضابطة وانئة وعددهيم (30) طالباً

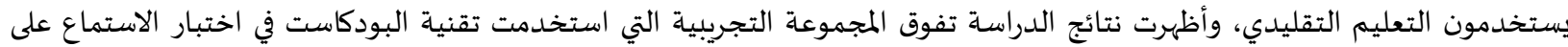
المجموعة الضابطة التي استخدمت التعليم التقليدي. 
تعقيب على الدراسات السابقة وموقع الدراسـة الحالية منها:

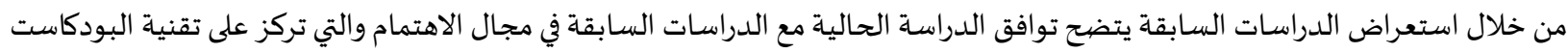
ومهارة الاستماع باللغة الإنجليزية، كما توافقت في المنهج المستخدم والذي هو المنهج شبه التجريبي القائم على تقسيم العينة إلى مجموعتين تجريبية وضابطة، حيث أكدت جميعها على ضرورة توظيف تقنية البودكاست في العملية التعليمية لدورها الفعال في رفع التحصيل الدراسي لدى الطيات الطلبة. وتميزت هذه الدراسة عن الدراسات السابقة بأها وظفت تقنية البودكاست في تنمية مهارة الاستماع باللغة الإنجليزية على عينة من مرحلة التعليم

الأساسي وخصوصاً الصفوف الدنيا وهم طلاب الصف الأول الأساسي كون مرحلة الحلقة الأولى أهم مرحلة لتكوين مهارات اللغة الإنجليزية.

3.

1.3. منهج الدراسة وتصهميمه:

تم استخدام المنهج شبه التجريبي للمجموعتين التجريبية والضابطة مع القياس القبلي البعدي، ويوضح الشكل (1) التصميم

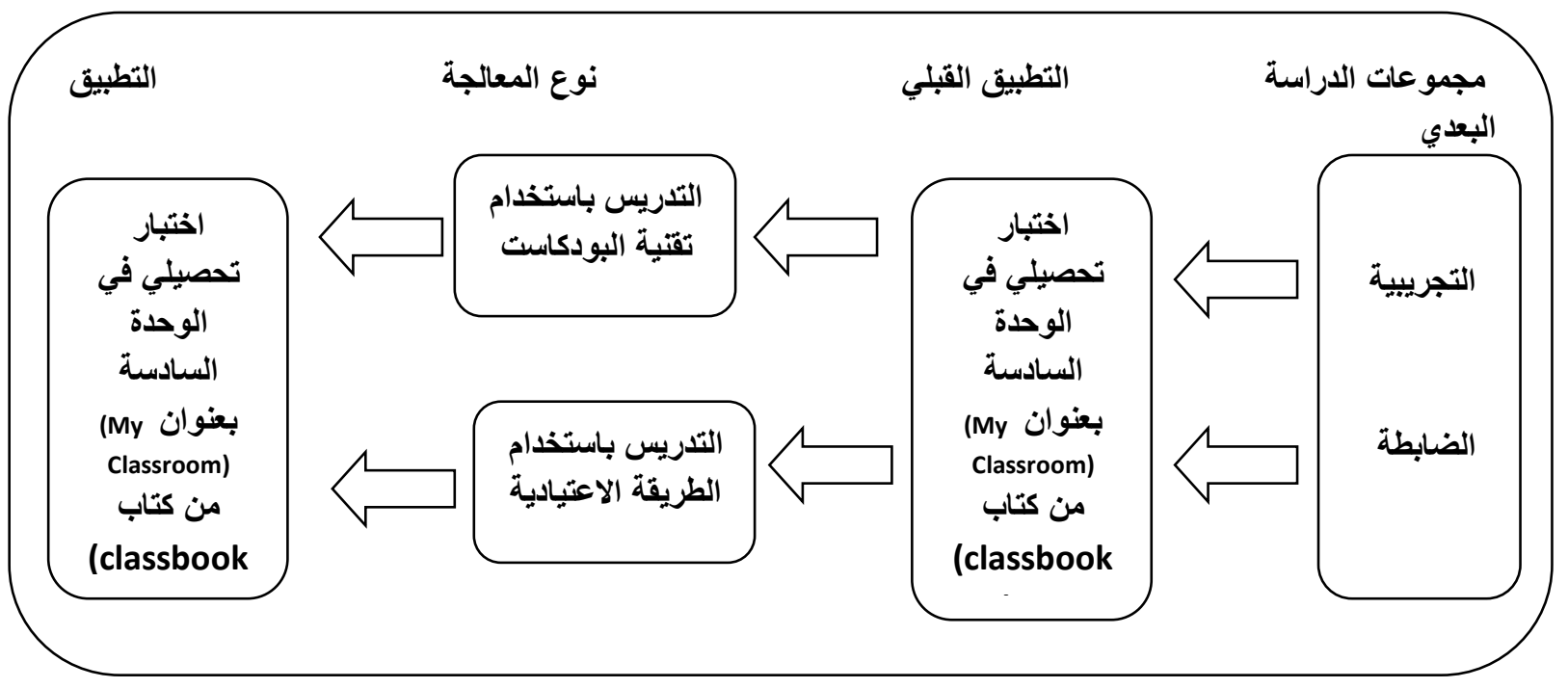

شكل (1): التصيميم شبه التجريبي للبحث

2.3. مجتمع وعينة الدراسـة:

تكون مجتمع الدراسة من جميع طلاب الصف الأول بمحافظة جنوب الباطنة والبالغ عددهم (159) طالباً وطالبة حسب الإحصائيات الصادرة

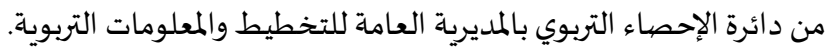
أما عينة الدراسة فتكونت من (54) طالباً وطالبة من طلاب الصف الأول بمدرسة وادي المعاول للتعليم الأساسي، تم مقسمين إلى مجموعتين التجريبية والضابطة تم اختيار الشعبتين من بين الشعب الست في المدرسة بالطريقة القصدية الشئ كون الباحثة معلمة المادة وفيها انتظام الطلبة في

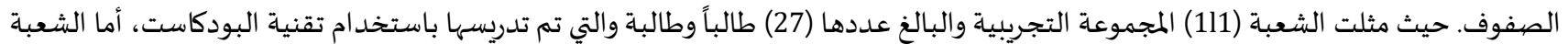

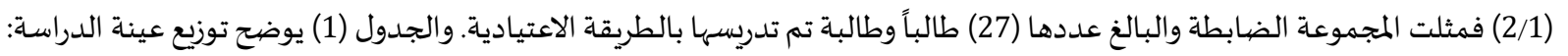

\begin{tabular}{|c|c|c|c|c|}
\hline مجموع أفراد العينة & عدد الطلاب & استر اتيجية التدريس & المجموعة & الشعبة \\
\hline \multirow{2}{*}{54} & 27 & تقنية البودكاست & التجريبية & أول/ أول \\
\hline & 27 & الطريقة الاعتيادية & الضابطة & أول/ثان \\
\hline
\end{tabular}

4.3. متغيرات الدراسـة: المتغير المستقل: ويتمثل في طريقة التدريس، وهي بمستويين هما: • تدريس المجموعة التجريبية باستخدام تقنية البودكاست. تدريس المجموعة الضابطة باستخدام الطريقة الاعتيادية. المتغيرات التابعة وتتمثل في:

مهارة الاستماع باللغة الإنجليزية الصف الأول الأساسي. 
المتغيرات الدخيلة: المتغيرات التي تم ضبطها بتوحيدها في الدراسة كي لا تؤثر في نتائجها وهي:

• المعلم: حيث تم اختيار معلم واحد ليقوم بتدريس المجموعتين: التجريبية والضابطة وذلك لاستبعاد أثر المعلم في نتائج الدراسية.

هالعمر الزمني لأفراد الدراسـة: حيث تم ضبط هذا المتغير، وذلك عن طريق اختيار طلاب من نفس المستوى الدراسي، وهم طلاب الصف الأول

الأساسي.

•المحتوى الدراسي: تم ضبط هذا المتغير، وذلك عن طريق تدريس المجموعتين التجريبية والضابطة نفس الوحدة الدراسية.

زمن التدريس: تمت مراعاة تدريس الوحدة الدراسية في نفس الفترة ونفس المدة الزمنية والتي بلغت أسبوعين حسب الخطة الدراسية للمادة

والمرتبطة بمهارة الاستماع.

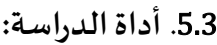

اعتمدت الدراسة الاختبار التحصيلي كأداة لقياس التحصيل الدراسي في مهارة الاستماع لموضيوعات مقررة على طلبة الصف الأول من التعليم

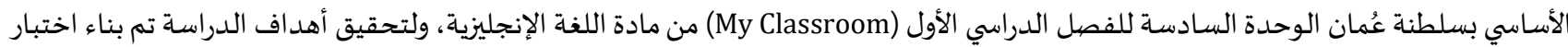

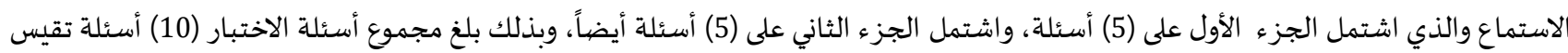

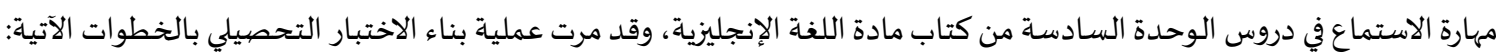
تحديد الهدف من الاختبار: يهدف الاختبار إلى قياس المعرفة القبلية لدى طلاب المجموعتين التجريبية والضابطة بالتركيز على مهارة الاستماع لتأكد من تكافؤ طلاب المجموعتين على الاختبار القبلي.

تحديد مهارة الاختبار: تم إعداد الاختبار ليشمل مهارة الاستماع باللغة الإنجليزية لدى طلاب الصفي الأول الأساسي بالمدرسـة. تحديد نوع الاختبار: تم اختيار الأسئلة باستخدام نمط الصواب والخطأ، هذا النوع من الاختبار يتميز بالموضوعية والسهولة وكذلك ربما

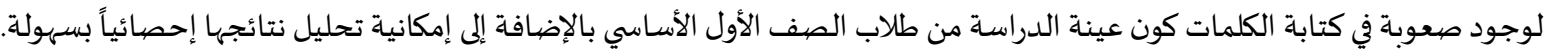

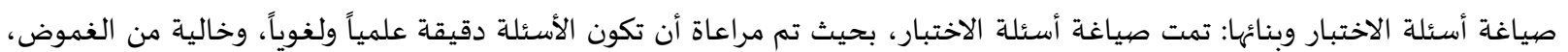

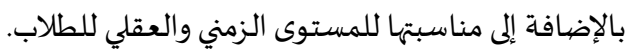
تم إعداد نموذج الإجابة الصحيحة من أسئلة الاختبار، وذلك لإتباع الدقة والموضوعية في احتسـاب الدرجات.

6.3. محتوى أداة الدراسـة:

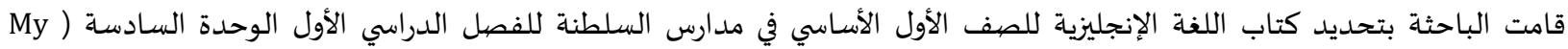

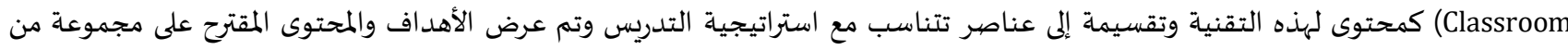

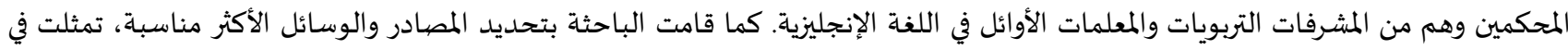
الوسائط المطلوبة لإنتاج وتصيميم البرنامج التعليمي (ملفات (PDF) وملفات البودكاست الصيوتية والمرئية وفيديوهات أنفوجرافيك التعليمي والمقاطع الصوتية (MP3) من خلال الجزء الخاص بالاستماع للنصيوص التي تحتويها الوحدة الدراسـة السادسة (My Classroom) من كتاب (Class book) من الفصل الدراسي الأول.

7.2

لتحقق من صدق أداة الدراسـة، تم عرض البرنامج والاختبار التحصيلي (القبلي- والبعدي) لقياس تنمية مهارة الاستماع باللغة الإنجليزية في

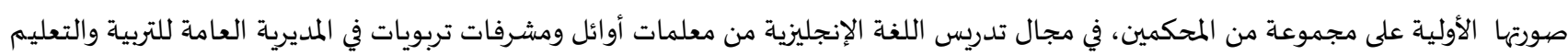

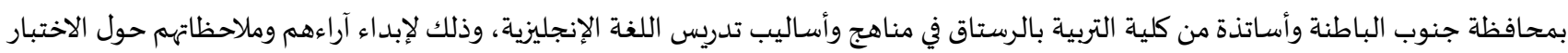

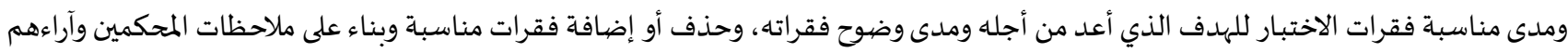
تم تعديل بعض فقرات الاختبار التحصيلي حتى أصبح بصورته النهائية.

8.3 ثبات أداة الدراسـة:

للتحقق من ثبات أداة الدراسة تم تطبيق الاختبار على عينة استطلاعية من خارج عينة الدراسة تكونت من (20) طالباً وطالبة من طلاب الصف كأف

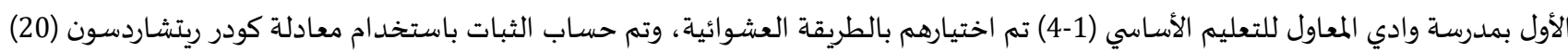
وكان يساوي (0,89) وهي قيمة مرتفعة وهذا يدل على وجود ثبات للاختبار.

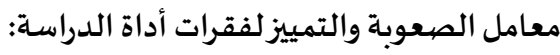
تم حساب قيم معاملات الصعوبة والتمييز للفقرات، والجدول (3) يبين نتائج ذلك. 


\begin{tabular}{|c|c|c|}
\hline معامل التمييز & معامل الصعوبة & الفقرة \\
\hline 0.660 & 0.401 & 1 \\
\hline 0.582 & 0.725 & 2 \\
\hline 0.694 & 0.632 & 3 \\
\hline 0.386 & 0.601 & 4 \\
\hline 0.694 & 0.603 & 5 \\
\hline 0.716 & 0.525 & 6 \\
\hline 0.434 & 0.495 & 7 \\
\hline 0.463 & 0.524 & 8 \\
\hline 0.692 & 0.443 & 9 \\
\hline 0.393 & 0.675 & 10 \\
\hline
\end{tabular}

يتبين من الجدول (3) أن قيم معاملات الصعوبة تراوحت بين (0.401) وبين (0.725)، وأن قيم معاملات التمييز تراوحت بين (0.386) وبين

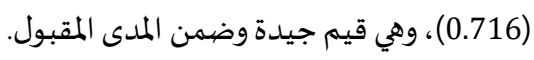
التحقق من تكافؤ المجموعتين قبل التطبيق: تم التحقق من تكافؤ المجموعتين باستخدام اختبار (ت) على نتائج القياس القبلي، والجدول (2) يبين نتائج ذلك. جدول (2): نتائج التحقق من تكافؤ المجموعتين على الاختبار القبلي

\begin{tabular}{|c|c|c|c|c|c|}
\hline مستوى الدلالة & درجات الحرية & قيمة & المعياري & الحسابي & المجموعة \\
\hline \multirow{2}{*}{0.183} & $5 ?$ & 1240 & 0.953 & 5.703 & التجريبية \\
\hline & JL & 1.047 & 1.754 & 5.185 & الضابطة \\
\hline
\end{tabular}

يتبين من الجدول (2) عدم وجود فروق بين المتوسطات الحسابية للمجموعتين، وهذا يدل على تكافؤ المجموعتين، حيث بلغت قيمة (ت) (1.349) وهي قيمة غير دالة عن مستوى الدلالة (0.183) مما يشير إلى تكافؤ المجموعتين في المستوى مما يعني بصلاحية تطبيق الدراسة على المان المجموعتين.

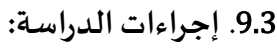

بعد الاطلاع على الأدب التربوي ثم تحديد مشكلة الدراسة، وأسئلته ومتغيراته والتعريفات الإجرائية للبحث والإطار النظري والدراسات السابقة،

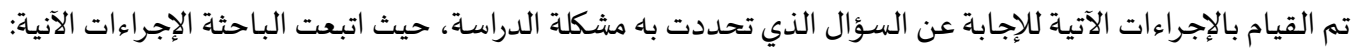

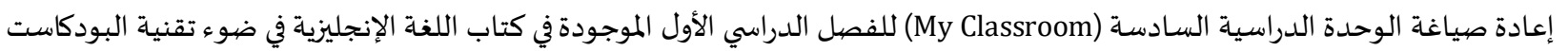
من حيث الأهداف والمحتوى والأنشطة والاختبارات القصيرة في مهارة الاستماع. تصميم مقاطع صوتية وفيديوهات الانفوجرافيك وملفات (pdf) قائمة على تقنية البودكاست لمحتوى الوحدة المراد تدريسها والمرتبطة بمهارة الاستماع. عرض أدوات الدراسة على مجموعة من المحكمين والاستفادة من آراءهم وملاحظاتهم في التعديل. إعداد الصهورة الهائية لأدوات الدراسة في ضوء آراء المحكمين وملاحظاتهم. • اختيار عينة الدراسة بالطريقة القصدية كون الباحثة معلمة المادة.

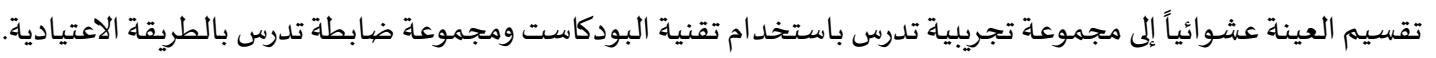
للتأكد من تكافئ وتماثل المجموعات تم إخضاع عينة الدراسة التجريبية والضابطة للتطبيق الاختبار القبلي. التحقق من ثبات الاختبار تم تطبيقه على عينة عشوائية من طلاب الصف الأول الأساسي من خارج عينة الدراسة وتم حساب معامل الثبات باستخدام معادلة كودر ريتشاردسون (20).

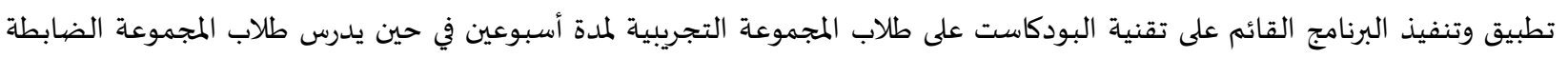
بالطريقة الاعتيادية. لملتأكد من مدى فاعلية البرنامج التعليمي (تقنية البودكاست) تم إخضاع المجموعتين التجريبية والضابطة للتطبيق البعدي للاختبار. تصحيح الاختبار وجمع البيانات. معالجة البيانات إحصائياً بواسطة البرنامج الإحصائي SPSS ورصد الدرجات. تحليل نتائج الدراسة ومناقشتها وتفسيرها، وتقديم التوصيات والمقترحات في ضوء نتائج الدراسة. 
10.3. المعالجات الإحصائية المستخدمة بالدراسـة:

تم حساب معامل ثبات الاختبار باستخدام معادلة كودر ريتشاردسون (20). تم التأكد من تكافؤ المجموعتين التجريبية والضابطة قبل البدء بتطبيق الدراسـة عن طريق حساب المتوسطات الحسابية والانحرافات المعيارية،

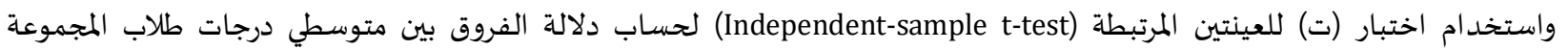
التجريبية في التطبيق البعدي لاختبار التحصيلي لمهارة الاستماع. حساب حجم الأثر للمتغير المستقل للبحث باستخدام اختبار (ت) للعينات المستقلة.

4. نتائج الدراسة ومناقشتها: 1.4. النتائج المتعلقة بالسؤال الأول الذي ينص على: ما أثرتوظيف تقنية البودكاست في تنمية مهارة الاستماع لدى طلاب الصف الأول بمحافظة جنوب الباطنة؛ للإجابة على السؤال تم صياغة الفرض التالي: لا توجد فروق ذات دلالة إحصائية عن مستوى الدلالة (0.05 م) بين متوسط درجات طلاب

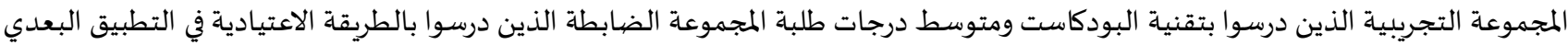
لاختبار مهارة الاستماع. ولاختبار الفرض تم استخدام اختبار(ت) لعينتين مستقلتين، والجدول (4) يبين ذلك.

\begin{tabular}{|c|c|c|c|c|c|}
\hline مستوى الدلالة & الحرجة & قيمة & الانحراف المعياري & الوسط الحسابي & المجموعة \\
\hline 0.004 & 52 & 3.031 & $\begin{array}{l}2.06 \\
1.25\end{array}$ & $\begin{array}{l}7.89 \\
6.48\end{array}$ & التجريبية \\
\hline
\end{tabular}

يتبين من الجدول (4) وجود فروق بين المتوسطات الحسابية للمجموعتين، وكانت الفروق لصالح المجموعة التجريبية، وهذا يدل على وجود أثر لتوظيف تقنية البودكاست في تنمية مهارة الاستماع.

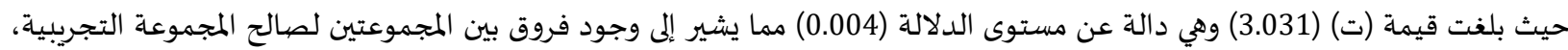
وهذا يشير بأن تقنية البودكاست كان لها تأثير إيجابي في تنمية مهارة الاستماع لدى طلاب المجموعة التجريبية. وتعزو الباحثة وجود أثر في توظيف تقنية البودكاست على تنمية مهارة الاستماع لدى طلاب الصف الأول في مدرسة وادي المعاول للتعليم الأساسي إلى طريقة عرض البرنامج، حيث تم عرض دروس الوحدة السادسة (My Classroom) من كتاب الطالب A1 Alassbook والمرتبطة بمهارة

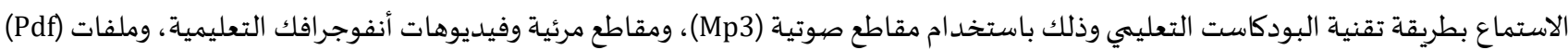
مما أدى إلى جذبهم وتشويقهم لدراسة البرنامج وتحقيق أهدافه، إضافة إلى دور تقنية البودكاست في توصيل المادة التعليمية للطلبة بطريقة سهلة وممتعة، وإثارة حماس ودافعية الطلاب نحو التعلم الأمر الذي ينعكس على التحصيل الدراسي لدى الطلبة، مما أتاح الفرصة لمزيد من لإتقان في التمان التعلم

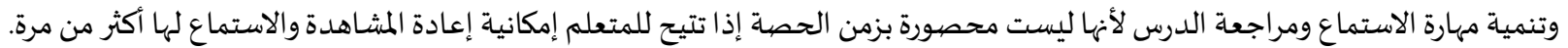

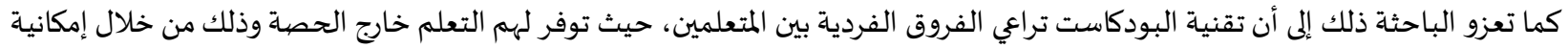

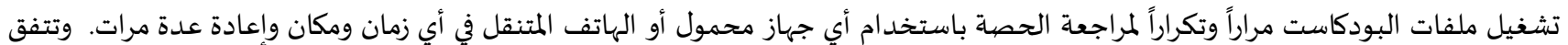
هذه النتيجة مع دراسة: الحارثي (2018)، ودراسة أبو المعاطي وآخرون (2015)، حيث أثبتت هذه الدراسات فاعلية توظيف تقنية البودكاست في تنمية مهارة الاستماع باللغة الإنجليزية. 2.4. النتائج المتعلقة بالسؤال الثاني الذي ينص على: هل توجد فروق يين متوسطي درجات طلاب المجموعة التجريبية الذين درسوا باستخدام

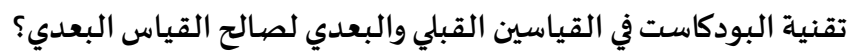

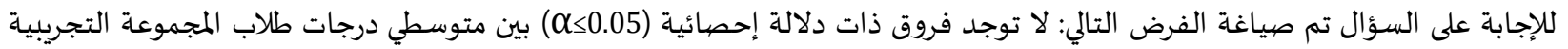
الذين درسوا بتقنية البودكاست في القياسين القبلي والبعدي لصالح القياس البعدي. ولفحص الفرض تم استخدام اختبار(ت) لعينتين مرتبطتين، والجدول (5) يبن نتائج ذلك.

جدول (5): نتائج اختبار(ت) لدلالة الفروق بين درجات المجمموعة التجريبية في الاختبار القبلي والبعدي

\begin{tabular}{|c|c|c|c|c|c|}
\hline مستوى الدلالة & درجات الحرية & قيمة & الانحراف المعياري & الوسط الحسابي & القياس \\
\hline \multirow{2}{*}{0.000} & \multirow{2}{*}{26} & \multirow{2}{*}{-4.855} & 0.953 & 5.703 & القبلي \\
\hline & & & 2.06 & 7.89 & البعدي \\
\hline
\end{tabular}


يتبين من الجدول (5) وجود فروق ذات دلالة إحصائية بين متوسطي درجات طلاب المجموعة التجريبية الذين درسوا باستخدام تقنية

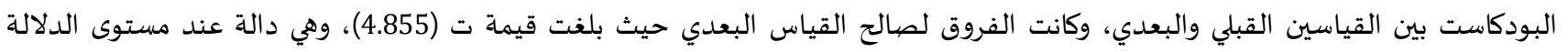

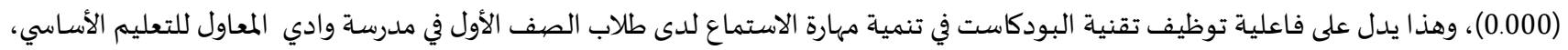
وتم حساب حجم الأثر وكان يساوي (0.48)، وهي قيمة تدل على فلى أن حجم الأثر كان كان كبيراً.

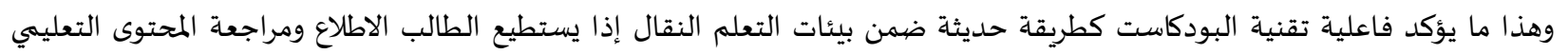

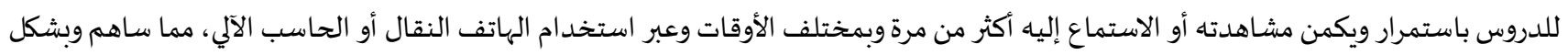

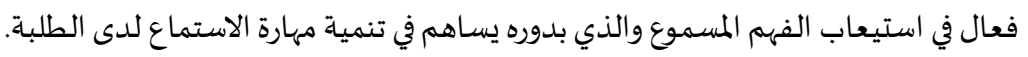
كما تعزو الباحثة ذلك إلى أهمية تقنية البودكاست في تسهيل عملية التعلم حيث توفر تقنية البودكاست المادة التعليمية للمتعلمين في كل مكان

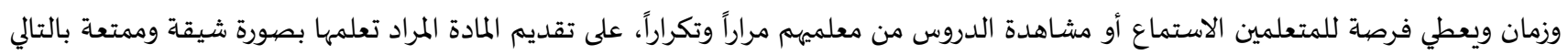

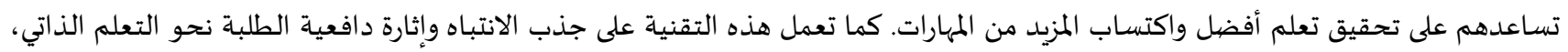

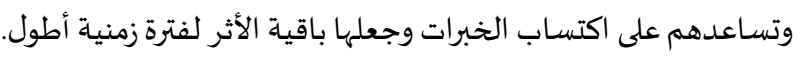

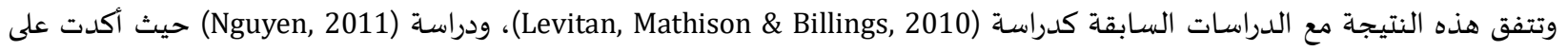
فاعلية توظيف التقنيات الحديثة وخاصة تقنية البودكاست التعليمي في تحسين وتطوير العملية التعليمية باعتبارها شكلاً من أشكال التعلم الإلكتروني.

ضرورة الاهتمام بتوظيف تقنية البودكاست في تنمية مهارة الاستماع، إذ أشـارت نتائج الدراسة الحالية إلى الأثر الكبير لهذه التقنية في تنمية مهارة الاستماع لدى طلبة الصف الأول.

ضهرورة توظيف تقنية البودكاست في جميع المراحل الدراسية والمواد الدراسية لما لها من أثر في زيادة فعالية التعلم من خلال التحصيل الدراسي. توفير الدعم المادي للتقنيات الحديثة في التعليم وخاصة تقنية البودكاست لما لها من آثار إيجابية على التدريس والتحصيل كشفت عنها نتائج الدراسـة. • أهمية تدريب المعلمين لإنتاج وتصميم ملفات البودكاست وتوظيفها في العملية التعليمية.

من خلال النتائج التي توصلت إلهها الدراسة الحالية، فإنها تقترح الآتي: إجراء المزيد من الدراسات والبحوث المماثلة لهذه الدراسة في مهارات اللغة الانجليزية الأخرى مثل التحدث والقراءة ومواد دراسية أخرى عامة. إجراء المزيد من الدراسات عن فاعلية تقنية البودكاست التعليمي في تنمية متغيرات أخرى. إجراء دراسة عن معوقات استخدام تقنية البودكاست في العملية التعليمية. 1. أكرم، حباء (2019). فاعلية برنامج تلدريبي قائم على بث الوسائط (البودكاست) في تنمية مهارات تلدبر النص القرآني لدى معلمات القرآن الكريم.

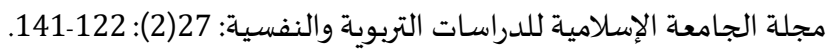

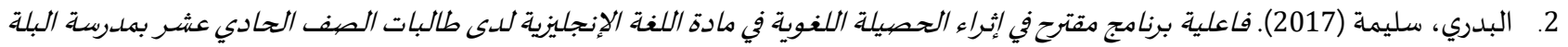

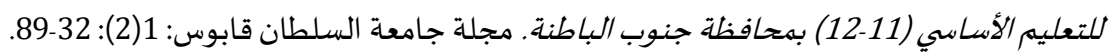

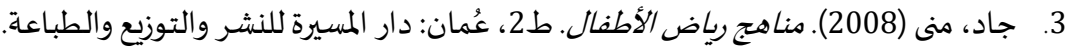

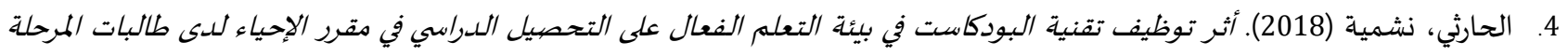

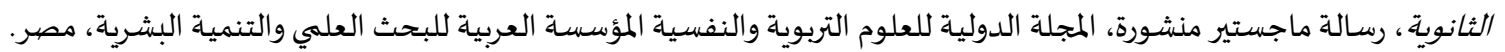
5. الحربي، سلمى (2016). فاعلية القصص الرقمية في تنمية مهارات الاستماع الناقد في مقرر اللغة الإنجليزية لدى طالبات المرحلة الثانوية في مدينة

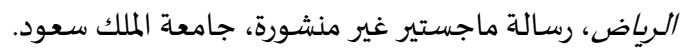
6. حلس، داود والشوبكي، مها (2017). فاعلية بزنامج قائمر على مهارات الاستماع لتنمية مهارات القراءة للدى تلميندات الصيف الرابع الأساسي بغزة. مجلة الجامعة الاسلامية: 2(2): 218-240. 
7 7. الخليفة، هند (2010). توظيف تقنيات ويب 2.0 في خلدمة التعليمروالتدريب الالكتروني .جامعة ساوث همبتون، ساوث همبتون :المملكة المتحدة.

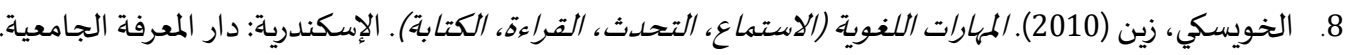

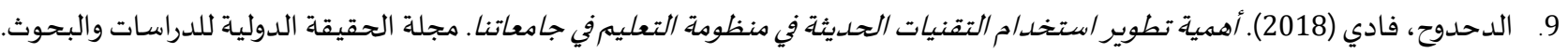

10. ساطور، محمد (2011). تفعيل دور البودكاست كوسيط إعلاني متحك جلديل، قسم الإعلان، كلية الفنون التطبيقية، جامعة حلوان، مصر.

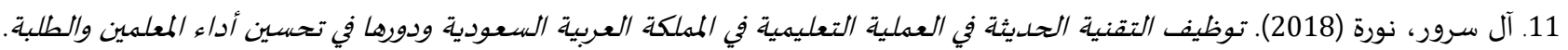

مجلة العلوم التوبوية والنفسية: $4(2): 18$-18

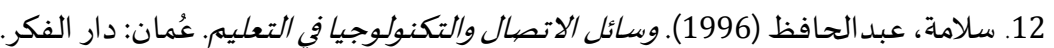

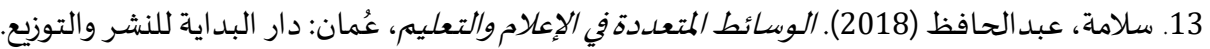

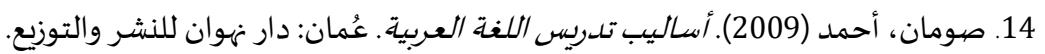

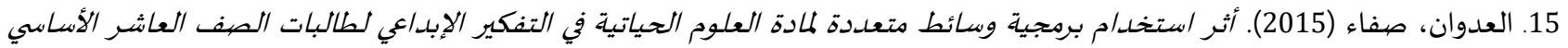

واتحجاهاتهن نحوها. (رسالة ماجستير غير منشورة). جامعة الشرق الأوسط الأردن.

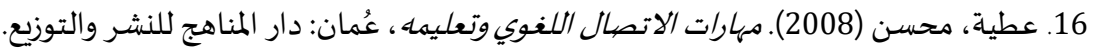

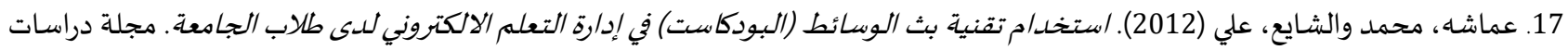

المعلومات: (13): 165-87.

18. العنزي، طلال (2018). درجة استخدام التقنيات التعليمية في تدريس التوبية الإسلامية للمرحلة المتوسطة من وجهة نظر المعلمين في دولة الكويت. رسالة ماجستير غير منشورة. جامعة آل البيت.

19. الغامدي، منال (2018). فاعلية البودكاست التعليمي في تنمية مهارة التحلدث باللغة الإنجليزية لدى طالبات المرحلة المتوسطة بالباحة، ، رسالة

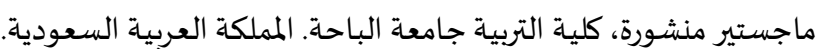

20. كامل، عماد (2005). فاعلية برنامج وسائط متعلددة لإكساب الطلاب المعلمين بكليات التربية مهارات الستخدام الفصيول الالكترونية، رسالة

ماجستير غير منشورة كلية التربية، جامعة عين شمس.

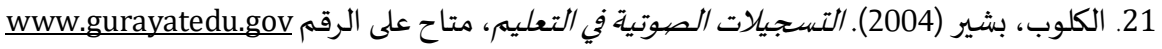

22. ماجد، خطايبة (2000). قياس مهارة القراءة ضمن مستويات التذكر والاستيعاب والتطبيق لدى طلبة معلم مجال اللغة الإنجليزية في جامعة

مؤتة. مجلة مؤتة للبحوث والدراسيات: 18 (1): 120-135.

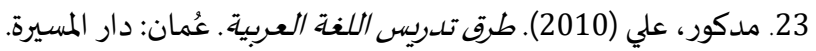

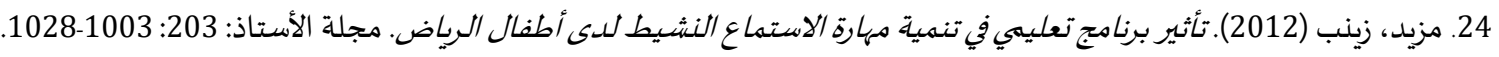

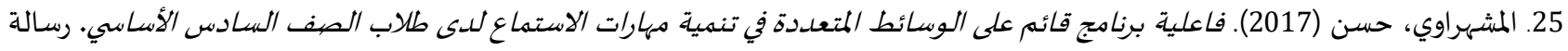

ماجستير منشورة، الجامعة الإسلامية غزة، كلية التربية، فلسطين.

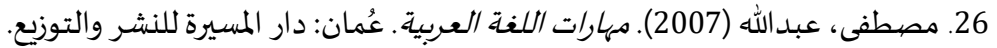

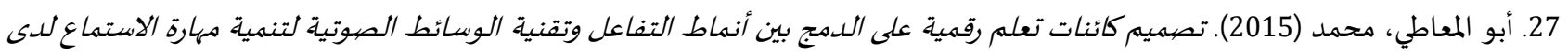

$$
\text { طاب الصيف الأول الثانوي، رابط التربويين العرب. }
$$

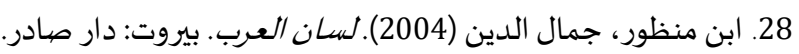

29. هادي، نور (2011). الموجه لتعليم المهارات اللغوية لغير الناطقين بها. ماليزيا: مطبعة جامعة مولانا مالك إبراهيم الإسلامية.

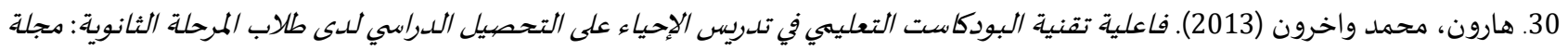

كلية التوبية: 2(3): 43-67.

ثانياً: المراجع الأجنبية:

1. Al-Qasim, N. \& Al-Fadda, H. (2013). The Effectiveness of Podcast on EFL Higher Education Students' Listening Comprehension. English Language Teaching. 6(9): 30-41. https://doi.org/10.5539/elt.v6n9p30

2. Brown, H. (2014). Teachers Attitudes and Confidence in Technology Integration, (unpublished master thesis), Marshall University, USA.

3. Goldman, T. (2018). The Impact of Podcasts in Education Advanced Writing: Pop Culture Intersections. 29. https://scholarcommons.scu.edu/engl 176/29 
4. Khany, R. \& Abol- Nejadian, R. (2010). The Effect of Podcast on Iranian EFL Learners' Listening Comprehension. 3rd edition of the ICT for Language Learning Conference. Tehran, Iran.

5. Levitan, M., Mathison, C. \& Billings, E. (2010). The Effect of Primary language podcasts on third grade English leaner's Performance in English -only Science Education contexts Electronic. Journal of literacy through Science. 9.

6. Liu, T. \& Chu, Y. (2010). Using ubiquitous games an English listening and speaking course. Impact on learning outcomes and motivation. computers \&Education, 55(2): 630-643. https://doi.org/10.1016/j.compedu.2010.02.023

7. Locker, M. (2018). Apple's podcasts just topped 50 billion all-time downloads and streams. [online] Fast Company. Available at: https://www.fastcompany.com/40563318/apples-podcasts-just-topped-50-billion-alltime-downloads-and-streams [Accessed 7 April. 2021].

8. Nair, G. (2012). ICT and teachers' attitude in English Language Teaching. Asian Social Science, 8 (11): 8-12.

9. Nguyen, D. (2011). Effectiveness of podcast lectures in English-writing courses for foreign-born learners at California BayArea community colleges. (3507049 Ed.D.), University of Phoenix, Ann Arbor. ProQuest Dissertations \& Theses Global database.

10. Stanley. G. (2005). Podcasting for ELT. Retrieved April 13, (2021) from: http://www.teachingenenglish.org.uk/think/resources LPodcasting.shtml.

11. Sulaiman, 0. (2017). The Attitudes of English Teachers toward Educational Technology in Teaching English and their Relation to the Degree of its Utilization in Primary Schools in the Governorate of Baghdad, (Unpublished master thesis), Middle East University, Jordan.

12. Susan, F. Martin, L. Shaw, J. \& Daughenbaugh, L. (2014). Using Smart Boards and Manipulative in the Elementary Science Classroom. Tech. Trends: Linking Research \& Practice to Improve Learning. 58 (3): 90-96. https://doi.org/10.1007/s11528014-0756-3 


$$
\text { المجلة الدولية للدراسـات التربوية والنفسية }
$$

International Journal of Educational \& Psychological Studies (EPS)

Journal Homepage: https://www.refaad.com/views/EPSR/Home.aspx

www.refaad.com

ISSN: 2520-4149 (Online) 2520-4130 (Print)

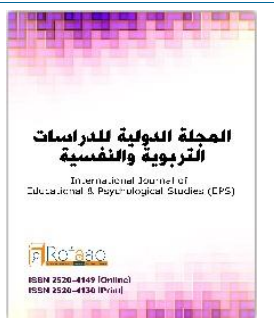

\title{
The impact of the use of podcast technology in the development of listening skills in the English language for first grade in South Batinah governorate
}

\section{Eman bint Mohammad bin Zaid Al-Ma'awaliyah}

Ministry of Education, Sultanate of Oman

qazaqmah@yahoo.com

\author{
Received : 24/3/2021 Revised:8/4/2021 Accepted:17/4/2021 DOI : https://doi.org/10.31559/EPS2021.10.1.10
}

Abstract: The study aimed to identify the impact of the use of podcast technique in the development of listening skills in the English language for first grade in South Batinah Governorate. The sample included (45) students of the first-grade primary school with (27) students for the experimental group, and (27) for the control group. To achieve the objectives of the study, a reading test was developed before and after the end of the study. The results showed that there was an effect on the use of podcast technique in the development of listening skill in English language for first grade students in South Batinah Governorate. The results showed that the experimental group who studied using the podcast technique increased their listening skills to the control group in the test Dimensional achievement.

Keywords: podcast technology; of listening skills; English language.

\section{References:}

1. Al'dwan, Sfa' (2015). Athr Astkhdam Brmjyh Wsa't Mt'ddh Lmadh Al'lwm Alhyatyh Fy Altfkyr Alebda'y Ltalbat Alsf Al'ashr Alasasy Watjahathn Nhwha. (Rsalt Majstyr Ghyr Mnshwrh). Jam't Alshrq Alawst Alardn.

2. 'mashh, Mhmd Walshay', 'ly (2012). Astkhdam Tqnyh Bth Alwsa't (Albwdkast) Fy Edart Alt'lm Alalktrwny Lda Tlab Aljam'h. Mjlt Drasat Alm'lwmat: (13): 87-165.

3. Al'nzy, Tlal (2018). Drjt Astkhdam Altqnyat Alt'lymyh Fy Tdrys Altrbyh Aleslamyh Llmrhlh Almtwsth Mn Wjht Nzr Alm'Imyn Fy Dwlt Alkwyt. Rsalt Majstyr Ghyr Mnshwrh. Jam't Al Albyt.

4. 'tyh, Mhsn (2008). Mharat Alatsal Allghwy Wt'lymh, 'uman: Dar Almnahj Llnshr Waltwzy'.

5. Akrm, Hbh (2019). Fa'lyt Brnamj Tdryby Qa'm 'la Bth Alwsa't (Albwdkast) Fy Tnmyt Mharat Tdbr Alns Alqrany Lda M'Imat Alqran Alkrym. Mjlt Aljam'h Aleslamyh Lldrasat Altrbwyh Walnfsyh: 27(2): 122-141.

6. Albdry, Slymh (2017). Fa'lyt Brnamj Mqtrh Fy Ethra' Alhsylh Allghwyh Fy Madh Allghh Alenjlyzyh Lda Talbat Alsf Alhady 'shr Bmdrsh Alblh Llt'lym Alasasy (11-12) Bmhafzt Jnwb Albatnh. Mjlt Jam't Alsltan Qabws: 1(2): 32-89.

7. Aldhdwh, Fady (2018). Ahmyh Ttwyr Astkhdam Altqnyat Alhdythh Fy Mnzwmt Alt'lym Fy Jam'atna. Mjlt Alhqyqh Aldwlyh Lldrasat Walbhwth.

8. Alghamdy, Mnal (2018). Fa'lyt Albwdkast Alt'lymy Fy Tnmyt Mhart Althdth Ballghh Alenjlyzyh Lda Talbat Almrhlh Almtwsth Balbahh, Rsalt Majstyr Mnshwrh, Klyt Altrbyh Jam't Albahh. Almmlkh Al'rbyh Als'wdyh.

9. Hady, Nwr (2011). Almwjh Lt'lym Almharat Allghwyh Lghyr Alnatqyn Bha. Malyzya: Mtb't Jam't Mwlana Malk Ebrahym Aleslamyh.

10. Alharthy, Nshmyh (2018). Athr Twzyf Tqnyh Albwdkast Fy By't Alt'lm Alf'al 'la Althsyl Aldrasy Fy Mqrr Alehya' Lda Talbat Almrhlh Althanwyh, Rsalt Majstyr Mnshwrh, Almjlh Aldwlyh Ll'lwm Altrbwyh Walnfsyh Alm'ssh Al'rbyh Llbhth Al'lmy Waltnmyh Albshryh, Msr.

11. Harwn, Mhmd Wakhrwn (2013). Fa'lyt Tqnyh Albwdkast Alt'lymy Fy Tdrys Alehya' 'la Althsyl Aldrasy Lda Tlab Almrhlh Althanwyh: Mjlt Klyt Altrbyh: 2(3): 43-67. 
12. Hls, Dawd Walshwbky, Mha (2017). Fa'lyt Brnamj Qa'm 'la Mharat Alastma' Ltnmyh Mharat Alqra'h Lda Tlmydat Alsf Alrab' Alasasy Bghzh. Mjlt Aljam'h Alaslamyh: 2(2): 218-240.

13. Alhrby, Slma (2016). Fa'lyt Alqss Alrqmyh Fy Tnmyt Mharat Alastma' Alnaqd Fy Mqrr Allghh Alenjlyzyh Lda Talbat Almrhlh Althanwyh Fy Mdynt Alryad, Rsalt Majstyr Ghyr Mnshwrh, Jam't Almlk S'ewd.

14. Jad, Mna (2008). Mnahj Ryad Alatfal. T2, 'uman: Dar Almsyrh Llnshr Waltwzy' Waltba'h.

15. Kaml, 'mad (2005). Fa'lyt Brnamj Wsa't Mt'ddh Leksab Altlab Alm'lmyn Bklyat Altrbyh Mharat Astkhdam Alfswl Alalktrwnyh, Rsalt Majstyr Ghyr Mnshwrh Klyh Altrbyh, Jam't 'yn Shms.

16. Alkhlyfh, Hnd (2010). Twzyf Tqnyat Wyb 2.0fy Khdmh Alt'lym Waltdryb Alalktrwny. Jam't Sawth Hmbtwn, Sawth Hmbtwn: Almmlkh Almthdh.

17. Alkhwysky, Zyn (2010). Almharat Allghwyh (Alastma', Althdth, Alqra'h, Alktabh). Aleskndryh: Dar Alm'rfh Aljam'yh.

18. Alklwb, Bshyr (2004). Altsjylat Alswtyh Fy Alt'lym, Mtah 'la Alrqm www.gurayatedu.gov

19. Abw Alm'aty, Mhmd (2015). Tsmym Ka'nat T'lm Rqmyh 'la Aldmj Byn Anmat Altfa'l Wtqnyh Alwsa't Alswtyh Ltnmyh Mhart Alastma' Lda Tlab Alsf Alawl Althanwy, Rabt Altrbwyyn Al'rb.

20. Majd, Khtaybh (2000). Qyas Mharh Alqra'h Dmn Mstwyat Altdkr Walasty'ab Walttbyq Lda Tlbt M'lm Mjal Allghh Alenjlyzyh Fy Jam't M'th. Mjlt M'th Llbhwth Waldrasat: 18(1): 120-135.

21. Mdkwr, 'ly (2010). Trq Tdrys Allghh Al'rbyh. 'uman: Dar Almsyrh.

22. Abn Mnzwr, Jmal Aldyn (2004). Lsan Al'rb. Byrwt: Dar Sadr.

23. Almshhrawy, Hsn (2017). Fa'lyt Brnamj Qa'm 'la Alwsa't Almt'ddh Fy Tnmyh Mharat Alastma' Lda Tlab Alsf Alsads Alasasy. Rsalt Majstyr Mnshwrh, Aljam'h Aleslamyh Ghzh, Klyt Altrbyh, Flstyn.

24. Mstfa, 'bdallh (2007). Mharat Allghh Al'rbyh. 'uman: Dar Almsyrh Llnshr Waltwzy'.

25. Mzyd, Zynb (2012). Tathyr Brnamj T'lymy Fy Tnmyh Mharh Alastma' Alnshyt Lda Atfal Alryad. Mjlt Alastad: 203: 10031028.

26. Satwr, Mhmd (2011). Tf'yl Dwr Albwdkast Kwsyt 'lany Mthrk Jdyd, Qsm Ale'lan, Klyt Alfnwn Alttbyqyh, Jam't Hlwan, Msr.

27. Slamh, 'bdalhafz (1996). Wsa'l Alatsal Waltknwlwjya Fy Alt'lym. 'uman: Dar Alfkr.

28. Slamh, 'bdalhafz (2018). Alwsa't Almt'ddh Fy Ale'lam Walt'lym, 'uman: Dar Albdayh Llnshr Waltwzy'.

29. Al Srwr, Nwrh (2018). Twzyf Altqnyh Alhdythh Fy Al'mlyh Alt'lymyh Fy Almmlkh Al'rbyh Als'wdyh Wdwrha Fy Thsyn Ada' Alm'lmyn Waltlbh. Mjlt Al'lwm Altrbwyh Walnfsyh: 4(2): 18-35.

30. Swman, Ahmd (2009). Asalyb Tdrys Allghh Al'rbyh. 'uman: Dar Nhwan Llnshr Waltwzy'. 